\title{
Importance of glucagon in the control of futile cycling as studied in alloxan-diabetic dogs
}

\author{
H. L.A. Lickley ${ }^{1,2,3}$ F. W. Kemmer ${ }^{5}$, K. M.A. El-Tayeb ${ }^{2}$ and M. Vranic ${ }^{2,4}$ \\ ${ }^{1}$ Department of Surgery, Women's College Hospital and Departments of ${ }^{2}$ Physiology, ${ }^{3}$ Surgery and ${ }^{4}$ Medicine, University of Toronto, \\ Toronto, Canada; ${ }^{5}$ Department of Nutrition and Metabolism, University of Düsseldorf, Düsseldorf, FRG
}

\begin{abstract}
Summary. In order to determine the role of glucagon in futile or substrate cycling in diabetes, we measured tracer determined glucose kinetics during a combined infusion of $2-{ }^{3} \mathrm{H}-$ glucose (total glucose production) and $6{ }^{3} \mathrm{H}$-glucose (glucose production) in six alloxan-diabetic dogs. The animals received either a $420 \mathrm{~min}$ infusion of (1) somatostatin alone $\left(0.3 \mu \mathrm{g} \cdot \mathrm{kg}^{-1} \cdot \mathrm{min}^{-1}\right)$, (2) somatostatin with insulin replacement $\left(100 \mu \mathrm{U} \cdot \mathrm{kg}^{-1} \cdot \mathrm{min}^{-1}\right)$ or (3) glucagon $\left(6 \mathrm{ng} \cdot \mathrm{kg}^{-1}\right.$. $\min ^{-1}$ ) together with somatostatin and transient insulin replacement. When somatostatin was given alone, plasma glucagon $(p<0.004)$ and insulin $(p<0.0001)$ were suppressed. Glucose production and disappearance and plasma glucose concentrations fell $(p<0.0001)$, but the metabolic clearance of glucose did not change significantly. In the basal state, futile cycling comprised $29 \pm 4 \%, 33 \pm 4 \%$ and $33 \pm 3 \%$ of total glucose production in the three goups of studies, which is high compared to normal dogs. The absolute rate of futile cycling fell slightly but significantly from $10.0 \pm 1.7$ to $8.3 \pm$ $1.7 \mu \mathrm{mol} \cdot \mathrm{kg} \cdot{ }^{-1} \mathrm{~min}^{-1}(p<0.0008)$. When insulin replacement was given during somatostatin infusion to correct for the small somatostatin-induced insulin suppression, there were similar changes in plasma glucagon, glucose concentrations and glu-
\end{abstract}

cose kinetics as seen during the infusion of somatostatin alone. Futile cycling decreased to a slightly greater extent from $12.8 \pm 2.8$ to $9.5 \pm 1.7 \mu \mathrm{mol} \cdot \mathrm{kg}^{-1} \cdot \mathrm{min}^{-1} \quad(p<0.02)$. When glucagon was infused together with somatostatin and insulin replacement, plasma glucagon $(p<0.0002)$ increased and plasma glucose levels rose $(p<0.001)$ due to a transient increase in glucose production. Metabolic clearance of glucose did not change significantly. There was a marked increase in futile cycling from $12.2 \pm 1.7$ to $21.7 \pm 1.7 \mu \mathrm{mol}$. $\mathrm{kg}^{-1} \cdot \min ^{-1}(p<0.0001)$ in response to exogenous glucagon excess. There was a slight $(p<0.01)$ drop in free fatty acid levels with somatostatin. Free fatty acid levels nearly doubled $(p<0.025)$ with the infusion of glucagon together with somatostatin. In conclusion, (a) futile cycling was increased in alloxan-diabetic dogs; (b) glucagon suppression can suppress futile cycling only if total insulin deficiency is prevented; and (3) hyperglucagonaemia increases futile cycling, and this effect is more pronounced during insulin deficiency.

Key words: Total glucose appearance, glucose production, glucose disappearance, metabolic clearance of glucose, tracer-determined glucose turnover.
Glucagon suppression by somatostatin has been proven to be effective in decreasing plasma glucose levels in diabetic patients [1-3]. More recently, we have shown that glucagon suppression is effective in decreasing hepatic glucose production in alloxan-diabetic, but not depancreatized, insulin-deprived dogs [4], indicating that small amounts of insulin are required for the reversal of the glucagon-induced catabolic cascade [5].

In the normal or diabetic liver new glucose is produced by both glycogenolysis and gluconeogenesis. However, a portion of glucose taken up by the liver is not polymerized to glycogen or oxidized; rather, it reenters the circulation after phosphorylation followed by rapid dephosphorylation. These are two "non-equilibrium" reactions which are catalyzed by two separate en- zymes [6]. This constitutes a futile or substrate cycle which has been termed the glucose cycle [7]. Both the substrate and product are the same metabolite, and each turn of the cycle uses up a high-energy phosphate bond. There are two other futile cycles: the fructose6-phosphate cycle and the phosphoenolpyruvate cycle. Futile cycling is a separate consideration from recycling of radioactive 3-carbon fragments through the Cori $\mathrm{Cy}$ cle.

In normal dogs, futile or substrate cycling comprises $13-20 \%$ of the glucose output from the liver [8-11]. The activity of the glucose cycle is increased in normal animals after 45 min of selective insulin deficiency [11], in diabetic dogs [12] and in man [13], contributing to the overall increase in glucose production in these situa- 
tions. The increase in futile cycling of glucose could be due to insulin deficiency and/or excess of counterregulatory hormones in diabetes. It has been shown in normal animals that both glucagon $[9,11]$ and cortisol $[9$, 12] can increase futile cycling. The specific role of glucagon in regulating futile cycling in diabetes has not been established.

We wished to establish the role of glucagon in increased futile cycling in diabetes. As glucagon suppression decreased hepatic glucose production in alloxandiabetic dogs [4], we also wished to see whether this was due, at least in part, to a decrease in futile cycling. We therefore examined the effects of combined insulin and glucagon deficiency, selective glucagon deficiency and selective glucagon excess.

\section{Materials and methods}

\section{Preparation of experimental animals}

Diabetes was induced in six mongrel dogs weighing 18-22 kg using $60 \mathrm{mg} / \mathrm{kg}$ alloxan (Sigma, St. Louis, Mo, USA). At least 10 days before the commencement of the first study the animals underwent surgery to provide portal, jugular and saphenous vein cannulae [14]. The animals were treated with regular and Neutral Protamine Hagendornf (NPH) porcine insulin (Connaught Laboratories, Willowdale, Ontario, Canada) adjusted daily according to the degree of glycosuria [13, 15]. We have shown in previous studies that with such insulin therapy, the animals do not develop insulin antibodies for at least 2 months [16]. Each animal maintained their weight within $\pm 3 \mathrm{~kg}$, and they remained afebrile, healthy and were eating well throughout the period that they were being studied.

\section{Experimental design}

Two days prior to each experiment NPH insulin was stopped. The last dose of regular insulin was given at 16.00 hours the day before each study. Food was withdrawn $18 \mathrm{~h}$ before each study. The animals were trained to lie quietly during each experiment. The hematocrit was assessed before each study; if the hematocrit fell below $35 \%$, the study was abandoned.

Three experimental protocols were carried out on separate days, in which the dogs received (1) $3 \mathrm{~h}$ equilibrium and control period followed by a 7.5 -h infusion of somatostatin $\left(0.3 \mu \mathrm{g} \cdot \mathrm{kg}^{-1} \cdot \mathrm{min}^{-1}\right)$ and a 1-h recovery period; (2) an intraportal insulin $\left(100 \mu \mathrm{U} \cdot \mathrm{kg}^{-1} \cdot \mathrm{min}^{-1}\right)$ infusion during the somatostatin infusion in order to maintain plasma insulin at usual basal levels for these diabetic animals; or (3) intraportal glucagon $\left(6 \mathrm{ng} \cdot \mathrm{kg}^{-1} \cdot \mathrm{min}^{-1}\right)$ and insulin $\left(100 \mu \mathrm{U} \cdot \mathrm{kg}^{-1} \cdot \mathrm{min}^{-1}\right)$ given together with somatostatin $\left(0.3 \mu \mathrm{g} \cdot \mathrm{kg}^{-1} \cdot \mathrm{min}^{-1}\right)$ for $3 \mathrm{~h}$, after which the insulin infusion was stopped and glucagon and somatostatin were continued for a further $3 \mathrm{~h}$ in five animals. The three sets of studies were carried out in random order.

Cyclic somatostatin (Ayerst Laboratories, Montreal, Quebec, Canada) was dissolved immediately before use in normal saline containing $0.2 \%$ bovine serum albumin (fraction V, Armour Pharmaceuticals, Chicago, Ill, USA). Glucagon (Eli Lilly and Company Limited, Toronto, Ontario, Canada) was diluted in normal saline containing trasylol (Bayer AG, Leverkusen, FRG, KIU/dl saline) and the dogs' own plasma $(2 \mathrm{ml} / \mathrm{dl}$ saline adjusted to $\mathrm{pH} 8.5$ with bisodium hydroxide). Regular porcine insulin (Connaught Laboratories, Willowdale, Ontario, Canada) was diluted in normal saline containing the dogs' own plasma ( $2 \mathrm{ml} / \mathrm{dl}$ saline adjusted to $\mathrm{pH} 8.5$ with bisodium hydroxide).

\section{Tracer methods}

A primed constant infusion of a combination of $2-{ }^{3} \mathrm{H}$-glucose $(5 \mathrm{mCi}$ / $\mathrm{ml}$, New England Nuclear Canada, Lachine, Quebec, Canada) and $6{ }^{3} \mathrm{H}$-glucose $(5 \mathrm{mCi} / \mathrm{ml}$, New England Nuclear Canada) was given at a constant rate $(0.096 \mathrm{ml} / \mathrm{min})$ throughout the study. A priming dose equivalent to the amount infused in $150 \mathrm{~min}$ was given at the beginning of each experiment.

Using 2-H-glucose as tracer, the sum of glucose produced by glycogenolysis, gluconeogenesis and futile cycling (total glucose output or appearance) can be measured. Glucose turnover measured with $6-{ }^{3} \mathrm{H}$-glucose closely approximates glucose production $\left(\mathrm{R}_{\mathrm{a}}\right)$, because the sixth carbon is lost after glucose is metabolized to the point that it can no longer enter any of the futile cycles; it thus measures only glucose derived from glycogenolysis and gluconeogenesis. As a consequence, futile cycling of glucse can be calculated by subtracting glucose production measured by $6-{ }^{3} \mathrm{H}$-glucose from that measured using $2-{ }^{3} \mathrm{H}$-glucose.

The steady and non-steady state tracer infusion methods for calculating the rates of appearance $\left(R_{a}\right)$ and disappearance $\left(R_{d}\right)$ of endogenous glucose using a one compartment model have been described and validated in vivo [17-19]. It has been shown that this method does have to be modified during hyperinsulinaemic, euglycaemic clamps where glucose uptake is maximally increased [20], but conventional calculations appear valid under conditions such as those in the present study. Glucose clearance was calculated as $\mathrm{R}_{\mathrm{d}} / \mathrm{C}$, where C equals glucose concentration, but can also be directly derived from original tracer data in the same way as $R_{a}$ if the concentration of labelled glucose is measured rather than specific activity [21], and thus is a reliable measurement. Although the metabolic appearance of glucose does vary with plasma glucose concentrations, it is still clearly related to insulin action and thus is a useful parameter.

\section{Laboratory methods}

Blood samples for measurements of labelled and unlabelled glucose and immunoreactive insulin (IRI) concentrations were collected in dry heparinized tubes containing sodium fluoride as preservative. After centrifugation, plasma for determination of specific activity of glucose was deproteinized in equal volumes of $5 \%$ zinc sulphate and $0.3 \mathrm{~N}$ barium hydroxide. A 1-ml aliquot of the supernatant was evaporated to dryness in order to eliminate any tritium present as $3 \mathrm{H}_{2} \mathrm{O}$. The residue was redissolved in $1 \mathrm{ml}$ water and counted in Aquasol II (New England Nuclear Corporation, Boston, Mass, USA) by liquid scintillation spectrometry to obtain total specific activity $\left(2-{ }^{3} \mathrm{H}\right.$-glucose plus $6{ }^{3} \mathrm{H}$-glucose). A second aliquot of plasma was then subjected to a procedure to isolate the radioactivity originating from the $6{ }^{3} \mathrm{H}$-glucose [22]. The glucose from the sample, together with glucose carrier, was oxidized with periodic acid and the glucose molecule was thus broken into 5 formic acid molecules and 1 formaldehyde molecule. As the formaldehyde was formed from the 6 carbon atom of glucose, it contained all the tritium from the $6{ }^{3} \mathrm{H}$-glucose. The formaldehyde was precipitated with sodium arsenite and dimedone into an insoluable complex. After filtering, drying and weighing, the wafer was placed in acquasol II solution and counted by liquid scintillation spectrometry to obtain $6-{ }^{3} \mathrm{H}$-glucose specific activity. The $2 \cdot{ }^{3} \mathrm{H}$-glucose specific activity was calculated by subtracting this value from that for total specific activity. For each experiment an aliquot of the infused tracer infusion was prepared and treated in the same way as plasma samples, and counted in Aquasol II by liquid scintillation spectrometry. That portion of glucose production accountable by futile cycling was calculated by subtracting the rate of appearance of glucose measured using $6{ }^{-3} \mathrm{H}$-glucose as tracer from that measured using $2-{ }^{3} \mathrm{H}$-glucose.

The glucose-oxidase method was used for determination of plasma glucose levels (Glucose Auto Analyser, Beckman Instruments Incorporated, Fullerton, Calif, USA). Plasma IRI was determined by radioimmunoassay using an anti-beef insulin anti-serum (supplied through the courtesy of Dr. Peter Wright, Indianapolis, Ind, USA), a purified dog insulin standard and porcine insulin labelled with $I^{125}$ 


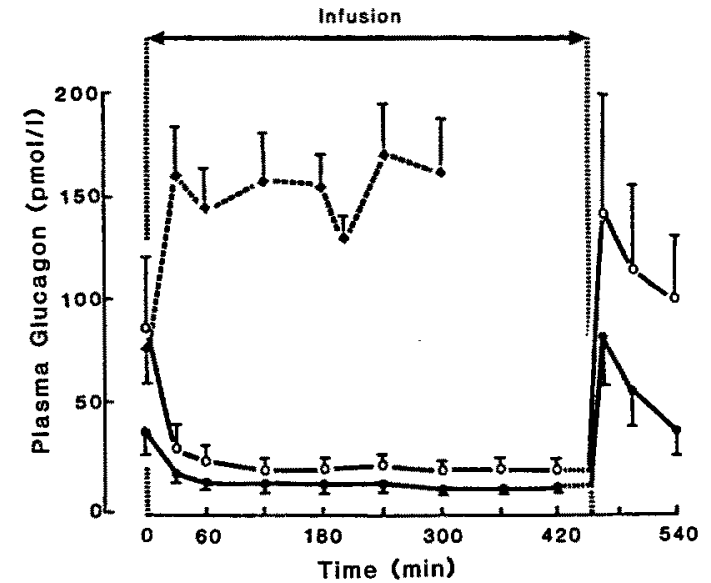

Fig. 1. Plasma glucagon (IRG) levels occurring in response to the infusion of (1) somatostatin alone $(-0),(2)$ somatostatin + insulin replacement $(\mathrm{O}-\mathrm{O})$ and (3) glucagon + somatostatin \pm insulin replacement (- Insulin was withdrawn in the third study at $180 \mathrm{~min}$. Values are presented as mean \pm SEM

(Novo Research Institute, Copenhagen, Denmark). Dextran-coated charcoal was used for the separation of free from bound hormones [23]. The method was modified by double-diluting the antibody, in order that the assay be sensitive to insulin concentrations as low as $4 \mu \mathrm{U} / \mathrm{ml}$. It was possible to measure plasma insulin accurately, as the animals had been treated with porcine insulin, which does not induce antibody formation for at least 2 months [16]. For the determination of plasma immunoreactive glucagon (IRG) and plasma free fatty acids (FFA), $4 \mathrm{ml}$ blood was added to chilled tubes, each containing $0.2 \mathrm{ml}$ EDTA $26 \mathrm{ml} / \mathrm{dl}$ and $0.2 \mathrm{ml}$ TRASYLOL (2000 KIU, FBA Pharmaceuticals, New York, NY, USA). Plasma glucagon was determined by radioimmunoassay [24] using $30 \mathrm{k}$ anti-serum (supplied by Dr. R.H. Unger, Dallas, TX, USA), which reacts with the C-terminal moity of ${ }^{3500} \mathrm{IRG}$ and ${ }^{125}$ I-labelled glucagon (Novo Research Institute). Plasma free fatty acid levels were determined by a radiochemical assay [25].

\section{Statistical analysis}

Values were presented at a mean $\pm S E M$, Statistical analysis was performed using the $S A S^{R}$ (statistical analysis system, SAS Institute Inc., Carey, N.C., USA). When responses to a treatment were assessed, we used a two-way analysis of variance. When individual points were compared within a study, a paired Student's t-test was used. Significance was presumed at $p<0.05$.

\section{Results}

\section{Hormonal responses}

As shown in Figure 1, somatostatin with $(\mathrm{F}=5.49, p<$ $0.02)$ or without $(\mathrm{F}=9.10, p<0.004)$ insulin replacement induced a sustained decrease in plasma glucagon (IRG) to levels close to the lower limits of sensitivity of the glucagon assay in each experiment. After the infusions were stopped, plasma IRG increased promptly. This allowed us to assess the effects of endogenous hyperglucagonaemia on glucose turnover and futile $\mathrm{cy}$ cling. With the infusion of glucagon together with somatostatin and insulin replacement, IRG rose rapidly

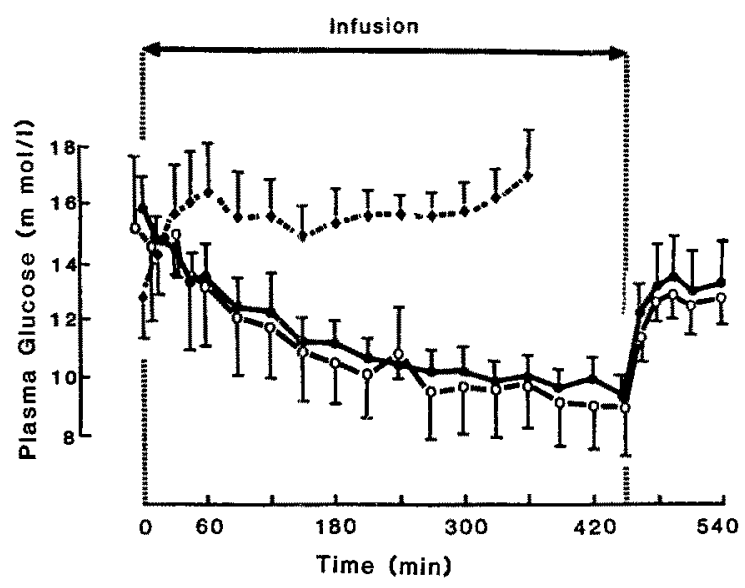

Fig. 2. Plasma glucose levels occurring in response to the infusion of (1) somatostatin alone $(-2)$, (2) somatostatin + insulin replacement $(\mathrm{O}-\mathrm{O})$ and $(3)$ glucagon + somatostatin \pm insulin replacement $(-)$. Insulin was withdrawn in the third study at $180 \mathrm{~min}$. Values are presented as mean \pm SEM

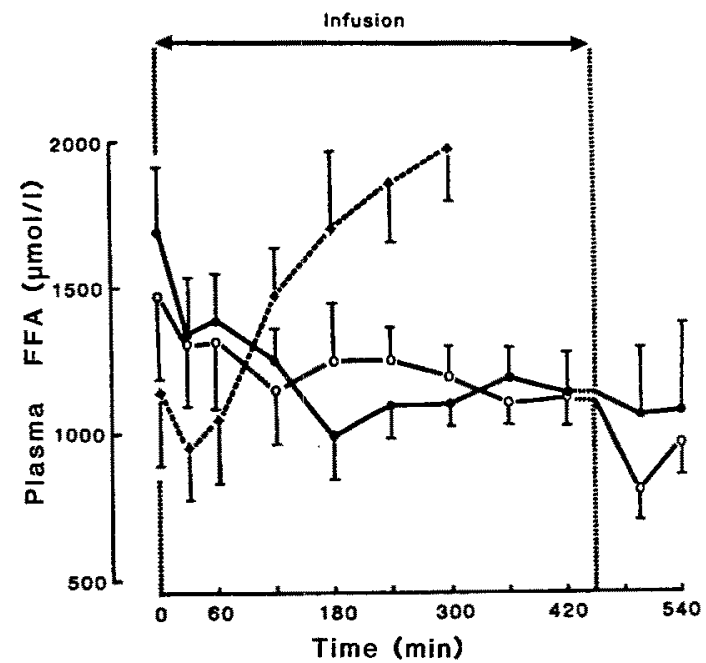

Fig. 3. Plasma free fatty acid (FFA) levels occurring in response to the infusion of (1) somatostatin alone (in tinsulin replacement $(\mathrm{O}-\mathrm{O})$ and (3) glucagon + somatostatin \pm insulin replacement $(\bullet)$. Insulin was withdrawn in the third study at $180 \mathrm{~min}$. Values are presented as mean $\pm S E M$

$(\mathrm{F}=16.7, p<0.0002)$ and remained elevated. When the insulin infusion was stopped, IRG did not rise further.

During the infusion of somatostatin alone (Table 1), the already decreased levels of plasma insulin (IRI) fell further $(\mathrm{F}=34.95, p<0.0001)$. When insulin $(100 \mu \mathrm{U}$. $\left.\mathrm{kg}^{-1} \cdot \mathrm{min}^{-1}\right)$ was given together with somatostatin, there was still a slight drop $(p<0.005)$ in IRI initially, but between 150 and $450 \mathrm{~min}$ IRI levels were not different from basal. After the infusions were stopped, plasma insulin values rebounded to suprabasal levels $(\mathrm{F}=38.83, p<0.0001$ after somatostatin alone; $\mathrm{F}=$ $14.63, p<0.0004$, somatostatin + insulin), indicating that some residual B-cell function was preserved in the alloxan-diabetic dogs. Since these levels were compara- 


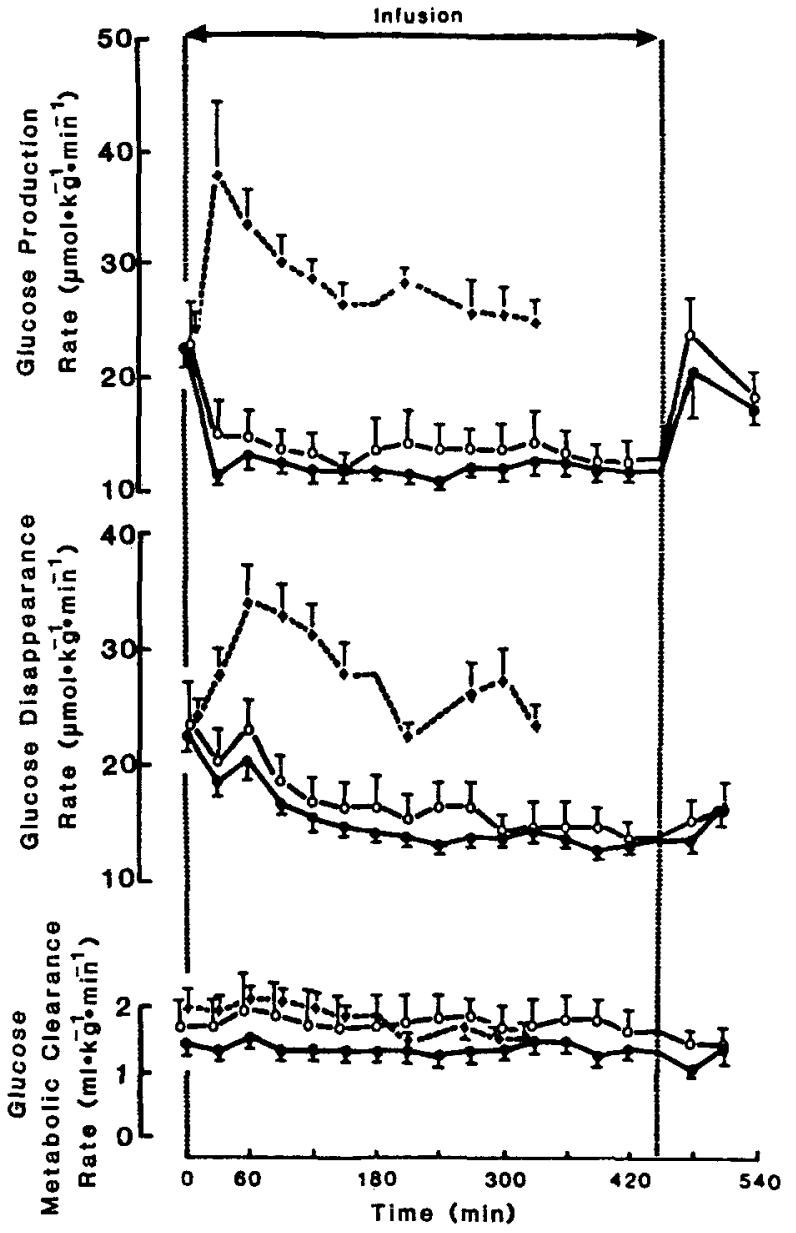

Fig. 4. Values for rates of true glucose production or appearance $\left(\mathbf{R}_{\mathrm{a}}\right.$, measured using 6-H-glucose as tracer), glucose disappearance $\left(R_{d}\right)$ and futile cycling $(F C)$ in response to the infusion of (1) somatostatin alone $(-12)$ somatostatin + insulin replacement $(0-0)$ and (3) glucagon + somatostatin \pm insulin replacement $(--\bullet)$. Insulin was withdrawn in the third study at $180 \mathrm{~min}$. The values plotted represent the mid-point of each time period over which $R_{a}, R_{d}$ and FC were measured and are presented as mean \pm SEM

ble to basal levels in normal dogs, we could determine the effects of endogenous hyperglucagonaemia in the presence of normal basal insulin levels. When glucagon was given with somatostatin and insulin replacement, there was a slight decrease in plasma IRI. After the insulin infusion was stopped, there was a further decrease in IRI plasma concentrations.

\section{Plasma glucose and free fatty acid levels}

During the infusion of somatostatin alone (Fig. 2), plasma glucose levels fell gradually from $15.8 \pm 1.1$ to $9.46 \pm 0.7 \mathrm{mmol} / 1 \quad(\mathrm{~F}=115.65, p<0.0001)$, then returned almost to basal after the end of the somatostatin infusion. When insulin was given to provide concentrations comparable to those usually seen in the basal state in alloxan-diabetic dogs, the somatostatin-induced decrease in plasma glucose from $15.8 \pm 2.5$ to $9.1 \pm$ $1.6 \mathrm{mmol} / 1(\mathrm{~F}=68.73, p<.0001)$ was almost identical to that seen when somatostatin was given without insulin replacement. After the infusion there was a similar restoration of plasma glucose toward basal values. During the infusion of glucagon together with somatostatin and insulin replacement, glucose rose significantly ( $\mathrm{F}=$ $42.55, p<0.0001$ ) but did not rise further after insulin was withdrawn.

During the infusion of somatostatin alone (Fig. 3), free fatty acid (FFA) levels fell from $1589 \pm 214$ to a nadir of $985 \pm 157 u \mathrm{~mol} / 1 \quad \mathrm{~F}=11.4, p<0.001)$. Plasma FFA levels did not rise after the end of the somatostatin infusion. When insulin replacement was given together with somatostatin, the drop in FFA $(\mathrm{F}=4.44, p<0.05)$ was somewhat smaller than with infusion of somatostatin alone. During the infusion of glucagon together with somatostatin and insulin replacement, basal FFA levels were $1144 \pm 171 \mu \mathrm{mol} / 1$ and rose continuously both during and after insulin withdrawal, reaching a final value of $1978 \pm 228 \mu \mathrm{mol} / 1$, which was significantly higher than basal $(p<0.025)$.

\section{Changes in tracer-determined glucose kinetics and futile cycling}

During the infusion of somatostatin alone (Fig.4, upper panel), hepatic glucose production $\left(\mathrm{R}_{\mathrm{a}}\right)$ fell from $22.8 \pm 1.7$ to $11.1 \pm 0.6 \mu \mathrm{mol} \cdot \mathrm{kg}^{-1} \cdot \mathrm{min}^{-1} \quad(\mathrm{~F}=85.56$, $p<0.0001$ ), then rose to near basal lavels following the end of the somatostatin infusion. When insulin replacement was given during the somatostatin infusion, there was an equivalent decrease in $\mathrm{R}_{\mathrm{a}}$ from $23.4 \pm 3.3$ to $12.2 \pm 1.7 \mu \mathrm{mol} \cdot \mathrm{kg}^{-1} \cdot \mathrm{min}^{-1} \quad(\mathrm{~F}=61.12, \quad p<0.0001)$. When glucagon was given together with somatostatin and insulin replacement, there was a prompt initial rise in $\mathrm{R}_{\mathrm{a}}$ from $23.9 \pm 1.7$ to $38.4 \pm 6.1 \mu \mathrm{mol} \cdot \mathrm{kg}^{-1} \cdot \mathrm{min}^{-1}$ $(p<0.05$ at 60 and $90 \mathrm{~min})$, and a gradual decline to $26.7 \pm 1.7 \mu \mathrm{mol} \cdot \mathrm{kg} \cdot{ }^{-1} \mathrm{~min}^{-1}$. When the insulin infusion was stopped, $R_{\mathrm{a}}$ remained stable.

During the infusion of somatostatin alone (Fig. 4, middle panel), the rate of disappearance of glucose $\left(R_{d}\right)$ fell from $22.8 \pm 1.7$ to $12.8 \pm 0.6 \mu \mathrm{mol} \cdot \mathrm{kg} \cdot{ }^{-1} \mathrm{~min}^{-1}$ $(\mathrm{F}=46.98, p<0.0001)$ but did not rise again significantly after the infusion. When insulin replacement was given with somatostatin, $R_{d}$ fell from $23.4 \pm 3.3$ to $13.9 \pm 1.7 \mu \mathrm{mol} \cdot \mathrm{kg} \cdot{ }^{-1} \mathrm{~min}^{-1} \quad(\mathrm{~F}=25.25, \quad p<0.0001)$. During the infusion of glucagon with somatostatin and insulin replacement, $R_{d}$ rose significantly $(F=9.27$, $p<0.0035$ ) but returned to basal by $150 \mathrm{~min}$. When insulin was stopped, $R_{d}$ remained near basal values. The metabolic clearance of glucose did not change significantly in any of the three sets of experiments.

There was a marginal decrease in absolute values for futile cycling from (FC) $10.0 \pm 1.7$ to $8.3 \pm$ $1.7 \mu \mathrm{mol} \cdot \mathrm{kg} \cdot{ }^{-1} \mathrm{~min}^{-1}$ (Table 2) during the infusion of somatostatin alone $(\mathrm{F}=7.32, p<0.008)$; however, when somatostatin was given with insulin replacement the decrease in FC was slightly greater, falling from $12.8 \pm 2.8$ to $9.5 \pm 1.7 \mu \mathrm{mol} \cdot \mathrm{kg} \cdot{ }^{-1} \mathrm{~min}^{-1} \quad(\mathrm{~F}=5.36, \quad p<0.02)$. 


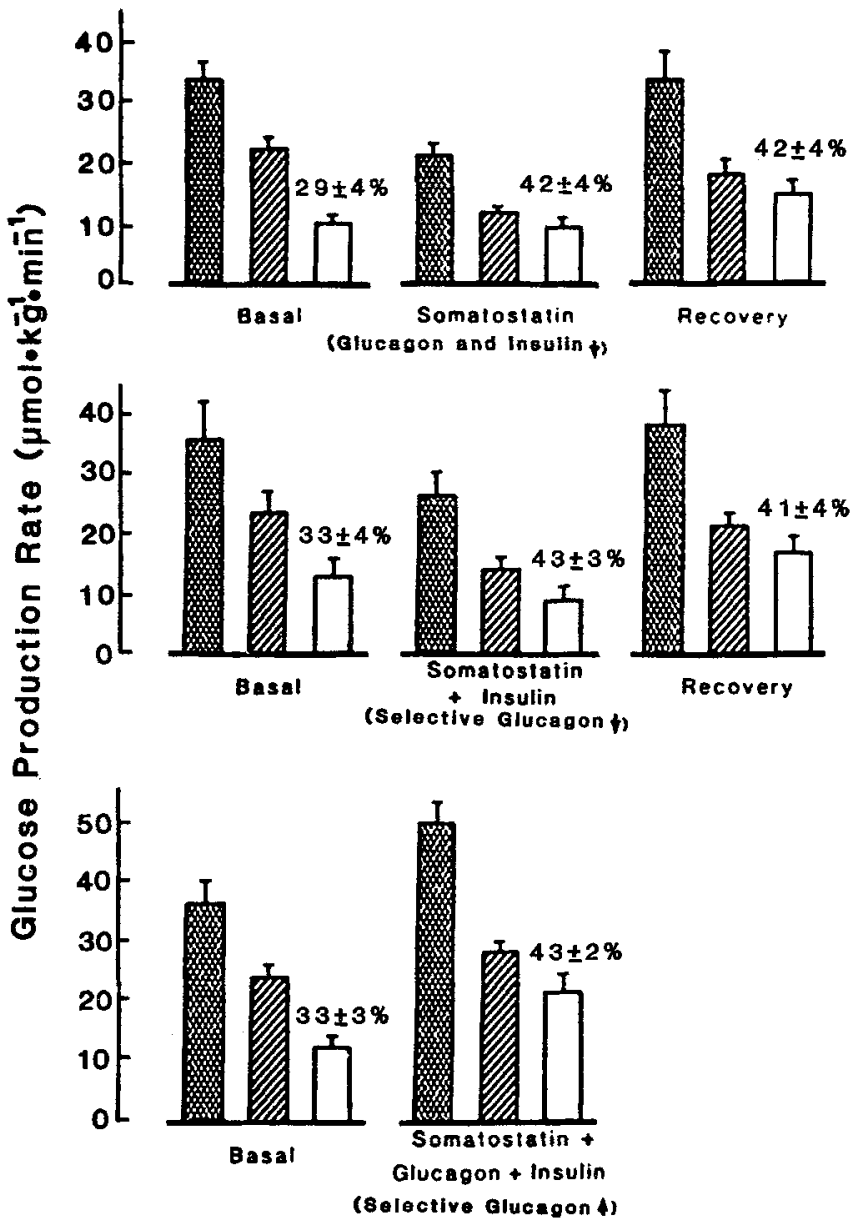

Fig.5. Figure 5 shows mean values for total glucose appearance calculated using $2{ }^{3} \mathrm{H}$-glucose glucose production calculated using $6{ }^{3} \mathrm{H}$-glucose ( sures futile cycling (FC) (D). Percentages refer to the percentage of total glucose appearance accounted for by futile cycling. Top panel gives basal rates for total glucose appearance, glucose production $\mathbf{R}_{a}$ and FC; overall responses to the infusion of somatostatin alone (rates between 120 and $450 \mathrm{~min}$ were averaged to obtain the overall response); and rates during the recovery period (rates between 450 and 540 min were averaged). Values are presented as mean \pm SEM. Middle panel gives basal rates for total glucose appearance, glucose production and FC; overall responses to the infusion of somatostatin + insulin replacement (rates between 120 and $450 \mathrm{~min}$ were averaged to obtain the overall response); and rates during the recovery period (rates between 450 and $540 \mathrm{~min}$ were averaged). Values are presented as mean \pm SEM. Bottom panel gives basal rates for total glucose appearance, glucose production and $\mathrm{FC}$, overall response to the infusion of glucagon + somatostatin \pm insulin replacement (rates between 120 and $150 \mathrm{~min}$ were averaged). Values are presented as mean \pm SEM

When glucagon was given together with somatostatin and insulin replacement, FC rose from $12.2 \pm 1.7$ to $21.7 \pm 1.7 \mu \mathrm{mol} \cdot \mathrm{kg} \cdot{ }^{-1} \mathrm{~min}^{-1} \quad(\mathrm{~F}=27.1, \quad p<0.0001)$. There was no further increase in FC when insulin infusion was stopped, but rather a decrease toward basal by the end of the infusion.

Figure 5 summarizes the overall changes in total glucose appearance (measured using $2{ }^{3} \mathrm{H}$-glucose), glucose production $\left(\mathrm{R}_{\mathrm{a}}\right.$, measured using $6{ }^{-3} \mathrm{H}$-glucose $)$ and FC during the three experimental studies. In these dia- betic animals, basal levels of glucose production were higher than seen in normal animals. In addition, the proportion of glucose production accounted for by $\mathrm{FC}$ was high, comprising between $29 \pm 4 \%$ and $33 \pm 4 \%$ of total glucose appearance. During the infusion of somatostatin alone (Fig. 5, upper panel), both total glucose appearance $(p<0.01)$ and $\mathrm{R}_{\mathrm{a}}(p<0.005)$ decreased, but the absolute rate of $\mathrm{FC}$ was unaltered. Thus, FC during glucagon suppression comprised $42 \pm 4 \%$ of total glucose appearance ( $p<0.02$ compared to basal). During the recovery period in which there was hyperglucagonaemia with normal insulin levels, total glucose appearance $(p<0.025)$ and $\mathrm{R}_{\mathrm{a}}(p<0.05)$ increased again. Futile cycling also increased, but remained at $42 \pm 4 \%$ of total glucose appearance $(p<0.0001$ compared to basal). With insulin replacement during somatostatin infusion (Fig. 5, middle panel), total glucose appearance $(p<0.01), \mathrm{R}_{\mathrm{a}}(p<0.005)$ and FC decreased. FC comprised $41 \pm 3 \%$ of total glucose production, but this increase was not significant; it was, however, significant in the recovery period $(43 \pm 4 \%, p<0.05$ compared to basal). When glucagon was given together with somatostatin and insulin (Fig. 5, lower panel), providing a selective increase in glucagon, total glucose appearance $(p<0.025)$ and FC $(p<0.01)$ increased, but final $\mathrm{R}_{\mathrm{a}}$ values did not change significantly. FC comprised $43 \pm 2 \%$ total glucose production ( $p<0.05$ compared to basal).

\section{Discussion}

We have examined the role of glucagon in the control of futile cycling in alloxanized dogs, an experimental model for diabetes, by assessing the effects of (1) combined insulin and glucagon deficiency, (2) glucagon deficiency with insulin replacement to prevent the somatostatin-induced decrease in plasma insulin and (3) glucagon excess, both (a) exogenous with hypoinsulinaemia and (b) endogenous accompanied by normoinsulinaemia. Combined glucagon and insulin suppression resulted in a decrease in glucose production $\left(R_{a}\right)$ but only a slight decrease in futile cycling (FC). When basal insulin levels were maintained during somatostatin infusion, glucagon suppression resulted in a decrease in both $\mathrm{R}_{\mathrm{a}}$ and FC. Glucagon excess resulted in an increase in both $\mathrm{R}_{\mathrm{a}}$ and $\mathrm{FC}$, and this was true whether the increase in plasma glucagon concentration was due to glucagon infusion or to endogenous glucagon release. The increase was smaller when normal basal insulin levels were present such as was seen during endogenous hyperglucagonaemia, although the glucagon levels achieved were perhaps slightly lower.

It is well recognized that glucagon and other counterregulatory hormones such as epinephrine and cortisol act synergistically to increase hepatic glucose production, particularly in diabetes [26], and it is possible that elevated levels of the catecholamines and cortisol in our alloxan-diabetic dogs could have interacted with 
glucagon and been responsible for part of the observed effects in our studies. We have recently carried out a study in alloxan-diabetic dogs in which we showed no significant difference in basal levels of these hormones from basal levels observed in normal control dogs [27]. Basal plasma glucose levels were virtually identical to those in our present study.

It is also well known that somatostatin suppresses growth hormone release, and it has been suggested [28] that this could enhance glucose disposal, counterbalancing the effects of insulin suppression. However, it has been shown [29] that when somatostatin was given during a combined insulin and glucagon clamp to maintain normal basal levels of these hormones, glucose turnover did not change significantly, indicating that the main glucoregulatory effects of somatostatin are through alterations in pancreatic hormone release. Also, a recent study [30] failed to show that somatostatin per se could increase insulin-stimulated glucose uptake.

In the basal state in our alloxan-diabetic dogs, between $29 \%$ and $33 \%$ of total glucose appearance was attributable to futile cycling. This is considerably more than the $13 \%-20 \%$ reported in normal dogs [8-11]. In normal man [31], futile cycling was approximately $10 \%$ of total glucose appearance. In Type 2 (non-insulin-dependent) diabetes [13], futile cycling was increased in the basal state and rose further during glucose infusion.

Futile cycling decreased slightly during bihormonal glucagon and insulin deficiency; when insulin was given together with somatostatin to restore insulin levels to the usual basal levels for these diabetic animals, futile cycling decreased to a somewhat greater extent. In order to restore futile cycling to normal values in diabetes, it may be essential to restore normoinsulinaemia as well as suppress plasma glucagon levels.

Not only did futile cycling increase during both endogenous and exogenous glucagon excess, but the proportion of total glucose production that was attributible to futile cycling also rose, suggesting that futile cycling is not a constant fraction of hepatic glucose production. One other study [32] suggests that futile cycling can change independently of glucose production, for it was shown that basal glucose production is increased by only $18 \%$ in acromegalic patients, as opposed to normal man, whereas futile cycling is increased by $76 \%$. However, when insulin infusion was stopped during infusion of glucagon and somatostatin, futile cycling did not increase further, suggesting that glucagon excess may be a greater determinant of the extent of futile cycling in diabetes than is the degree of insulin deficiency.

In normal dogs [10], when glucagon was infused at the same rate as in the present study and insulin was suppressed by somatostatin, futile cycling rose; by the end of the 75-min infusion period it accounted for $40 \%$ of the total glucose production. In normal dogs without insulin suppression, infusion of glucagon at 10 times the infusion rate as in the present study [9] resulted in an increase in futile cycling which was similar to that seen in our study, even though we used a much lower infusion rate. Also in the present study, the glucagon-induced increase in futile cycling was greater when hyperglucagonaemia was accompanied by hypoinsulinaemia. Thus, glucagon appears to be more effective in increasing futile cycling during hypoinsulinaemia. When normal dogs were given methylprednisolone for 3 days prior to the glucagon infusion [9], basal plasma glucose concentrations and $R_{a}$ were both elevated in the basal state. Thus, they were comparable in some respects to our alloxan-diabetic animals. However, they had an even higher basal rate of futile cycling than our alloxandiabetic animals. Futile cycling and total glucose production rose enormously when glucagon was given to these methylprednisolone-treated dogs, suggesting a synergistic effect of methylprednisolone and glucagon.

It is difficult to fully characterize the underlying biochemical abnormalities responsible for the increase in futile cycling in our alloxan-diabetic dogs, and the marked exacerbation of this defect during glucagon infusion. The activity of the glucose cycle depends on the rate of phosphorylation of glucose, its polymerization to glycogen, its glycolysis and dephosphorylation in the hexose isomerase reaction:

\section{glucose-6-phosphate $\rightleftarrows$ fructose-6-phosphate}

This reaction is considered to be non-rate limiting. The increase in futile cycling in diabetes could be due to a decreased activity of glycogen synthetase or increased activity of glucose-6-phosphatase or both. In alloxandiabetic rats, glucose-6-phosphatase activity is increased [33-35], and it is possible that this abnormality could be responsible for increased futile cycling both in diabetic man [13] and in our alloxan-diabetic dogs.

It has also been suggested [36] that the membrane translocase that transports glucose-6-phosphate from the extramicrosomal to the intramicrosomal compartment could be important in metabolic regulation. Thus, there could be a failure to appropriately recognize hyperglycaemia in diabetes, leading to increased activity of glucose-6-phosphatase which could, in turn, augment activity of the glucose cycle.

During the infusion of somatostatin alone, there was a slight though significant decrease in free fatty acids. Restoring insulin to previous basal levels in the alloxandiabetic animals in the present study did not enhance the effectiveness of glucagon suppression by further decreasing FFA levels. What was somewhat unexpected was the doubling in FFA levels in response to selective glucagon excess. Thus, glucagon appears to exert a lipolytic effect in hypoinsulinaemic alloxan-diabetic dogs. Glucagon has been shown to exert a lipolytic effect in isolated rat fat pads, but did not appear to have any effect on human adipocytes [37]. However, it has been shown recently that glucagon was lipolytic in perifused human adipocytes [38]. Glucagon has also been shown to decrease rather than increase FFA in normal dogs [39]. This could be due to stimulation of insulin release, 
both directly [40] and indirectly, through glucagon-induced hyperglycaemia. The marked increase in FFA in our study suggests that when insulin is subbasal, glucagon becomes a potent stimulator of lipolysis, as has been shown by other investigators [41]. It is possible that glucagon was lipolytic in the isolated adipocytes [38] because they too were in a hypoinsulinaemic environment. This has implications in the development of diabetic ketoacidosis; as insulin levels fall, glucagon rises, which can lead to excess production of FFA and ketone bodies [42].

The concept that glucagon is lipolytic in diabetes is further strengthened by studies in totally depancreatized insulin-deprived dogs, where somatostatin-induced glucagon suppression resulted in a significant decrease in FFA (unpublished observations). However, in similar studies [4] somatostatin had no effect on tracerdetermined glucose kinetics, suggesting that under conditions of severe chronic insulin deficiency, glucagon suppression was ineffective in improving carbohydrate metabolism. It also suggests that the effects of glucagon suppression on glucose metabolism can be dissociated from the effects on fat metabolism.

In conclusion, the present study demonstrates that (a) futile cycling is increased in alloxan-diabetic dogs, which provide an experimental model for diabetes; (b) glucagon suppression can decrease futile cycling in these diabetic animals, and this effect is intensified if the subnormal basal insulin levels in these animals are prevented from falling further; (c) both exogenous and endogenous hyperglucagonaemia can increase futile cycling; (d) this effect is less pronounced when insulin levels are normal (endogenous hyperglucagonaemia); (e) insulin deficiency appears to exaggerate glucagon's stimulatory effect on futile cycling; and (f) glucagon appears to be lipolytic under conditions of hypoinsulinaemia.

We feel that the data do not permit us to make firm conclusions with respect to the clinical implications of this study. However, we would like to postulate that in postabsorptive diabetes, as in our alloxan-diabetic dogs, futile or substrate cycling may increase to a greater extent than hepatic glucose production in response to stimuli such as hyperglucagonaemia. This could serve to protect hepatic glycogen stores by redirecting some glucose back into the liver, thus tending to ameliorate hyperglycaemia.

Acknowledgements. We are indebted to N. Kovacevic, D. Bilinski and E. Cook for their excellent assistance, to L. Payne, S. Dow and L. Cook for assistance in preparing this manuscript. We are grateful to Dr. R.Deghenghi (Ayerst Research Laboratories, Montreal, Quebec, Canada) for the generous gift of somatostatin which was used in these studies, to Connaught Laboratories (Willowdale, Ontario, Canada) for NPH and crystalized pork insulin and to Bayer AG (Leverkusen, FRG) for Trasylol. This work was supported by the Medical Research Council of Canada (MT-2197), the Canadian Diabetes Association, Juvenile Diabetes Foundation International and Women's College Hospital Research Fund. Dr. F. W. Kemmer was supported by the Deutsche Forschungsgemeinschaft and Dr. K.M.A. El-Tayeb was a doctoral student sponsored by the University of Gezira, Sudan.

\section{References}

1. Gerich JE, Lorenzi M, Schneider V, Karam JH, Guillemin R, Forsham PH (1974) The effects of somatostatin on plasma glucose and glucagon levels in human diabetes mellitus. $N$ Engl $J$ Med 291: 544-547

2. Raskin P, Unger RH (1975) Glucagon and diabetes. Med Clin North Am 62: 713-722

3. Unger RH (1976) Diabetes in the alpha cell: Banting Memorial Lecture 1975. Diabetes 25: 136-151

4. Lickley HLA, Kemmer FW, Doi K, Vranic M (1983) Glucagon suppression improves glucoregulation in moderate but not chronic severe diabetes. Am J Physiol 245: E424-E429

5. Unger RH, Foster DW (1985) Diabetes mellitus. In: Wilson JD, Foster DW (eds) Williams textbook of endocrinology. Saunders, Philadelphia, pp 1036-1039

6. Newsholme EA (1983) Regulation of glucose and fatty acid oxidation in relation to energy demand in muscle. In: Newsholme EA, Leech AR, (eds) Biochemistry for the medical sciences. John Wiley, Chichester, New York Brisbane, pp 300-335

7. Newsholme EA, Crabtree B (1976) Substrate cycles in metabolic regulations and in heat regulation. Biochem Symp 41: 61-110

8. Issekutz B Jr, Allen M, Borkow I (1972) Estimation of glucose turnover in the dog with glucose-2-T and glucose-U14C. Am J Physiol 222: 710-712

9. Issekutz B Jr (1977) Studies on hepatic glucose cycles in normal and methylprednisolone-treated dogs. Metabolism 26:157-170

10. Lickley HLA, Ross GG, Vranic M (1977) Effects of selective insulin or glucagon deficiency on glucose turnover. Am J Physiol 236: E255-E262

11. Vranic M, Lickley HLA, Kemmer FW, Perez G, Hetenyi G Jr, Hatton TW, Kovacevic N (1981) Interactions between insulin and the counterregulatory hormones in the development of diabetes. In: Martin JM, Ehrlich RM, Holland EJ (eds) Etiology and pathogenesis of insulin-dependent diabetes mellitus. Raven, New York, pp 153-178

12. Shaw WT, Issekutz T, Issekutz B Jr (1976) Gluconeogenesis from glycerol at rest and during exercise in normal, diabetic and methyprednisolone-treated dogs. Metabolism 25:329-339

13. Efendic S, Wajngot A, Vranic M (1985) Increased activity of the glucose cycle in the liver: Early characteristics of type 2 diabetes. Proc Natl Acad Sci USA 82: 2965-2969

14. Perez G, Kemmer FW, Lickley HLA, Vranic M (1985) Importance of glucagon in mediating epinephrine-induced hyperglycemia in alloxan-diabetic dogs. Am J Physiol 241: E328-E335

15. Kemmer FW, Lickley HLA, Gray DE, Perez G, Vranic M (1982) State of metabolic control determines role of epinephrine-glucagon interaction in glucoregulation in diabetes. Am J Physiol 242: E428-E436

16. Vranic M, Kawamori R, Pek S, Kovacevic N, Wrenshall GA (1976) The essentiality of insulin and the role of glucagon in regulating glucose utilization and production during strenuous exercise in dogs. J Clin Invest 57: 245-255

17. Cowan JS, Hetenyi G Jr (1971) Glucoregulatory response in normal and diabetic dogs recorded by new tracer method. Metabolism 18: 319-330

18. Radziuk J, Norwich K, Vranic M (1978) Experimental validation of measurement of glucose turnover in non-steady state. Am $\mathbf{J}$ Physiol 234: E84-E93

19. Radziuk J, Norwich K, Vranic M (1974) Measurement and validation of non-steady turnover rates with application to the insulin and glucose systems. Fed Proc 33: 1855-1864

20. Finegood DT, Bergman RN, Vranic M (1987) Estimation of endogenous glucose production during hyperinsulinemia euglycemic glucose clamps: comparison of unlabelled and labelled exogenous glucose infusates. Diabetes 36 (in press)

21. Radziuk J, Lickley HLA (1985) The metabolic clearance of glucose: Measurement and meaning. Diabetologia 28: 315-322

22. Reichard GA, Moury NF Jr, Hochella NJ, Patterson AL, Weinhouse $S$ (1963) Quantitative estimation of the Cori cycle in the human. J Biol Chem 238: 495-500 
23. Herbert V, Lau LS, Gottlieb CW, Bleicher S (1965) Coated charcoal immunoassay of insulin. J Clin Endocrinol Metab 25: $1375-1384$

24. Faloona GR, Unger RH (1974) Glucagon. In: Jaffe BN, Berman HR (eds) Methods of hormone radioimmunoassay. Academic Press, New York, pp 317-330

25. Ho RJ (1970) Radiochemical assay of long-chain fatty acids using ${ }^{63} \mathrm{Ni}$ as tracer. Anal Biochem 36: 105-113

26. Shamoon $H$, Hendler RS, Sherwin R (1981) Synergistic interaction among antiinsulin hormones in the pathogenesis of stress hyperglycaemia in humans. J Clin Endocrinol Metab 52: 1235-1241

27. Wasserman DH, Lickley HLA, Vranic M (1985) Important role of glucagon during exercise in diabetic dogs. J Appl Physiol 59: 1272-1281

28. Bergman RN, Ader M, Finegood DT, Pacini G (1984) Extra pancreatic effect of somatostatin infusion to increase glucose clearance. Am J Physiol 247: E370-E379

29. Cherrington AD, Chiasson J-L, Liljenquist JE, Jennings AS, Keller K, Lacy WW (1976) Role of glucagon in maintaining basal glucose production. J Clin Invest 58: 1407-1418

30. Baron AD, Wallace P, Brechteland G, Prager R (1987) Somatostatin does not increase insulin-stimulated glucose uptake in humans. Diabetes 36: 33-36

31. Karlander S, Roovete A, Vranic M, Efendic S (1985) Glucose and fructose-6-phosphate cycle in man. Am J Physiol 251: E530-E536

32. Karlander S, Vranic M, Efendic S (1986) Increased glucose turnover and glucose cycling in acromegalic patients with normal glucose tolerance. Diabetologia 29:778-783

33. Fisher CJ, Stetten MR (1966) Parallel changes in vivo in microsomal in organic pyrophosphatase, pyrophosphate-glucose phosphotransferase and glucose-6-phosphatase activities. Biochem $\mathrm{Bi}$ ophys Acta 121: 102-109

34. Jakobsson SV, Dallner G (1968) Nature of the increase in liver microsomal glucose-6-phosphatase activity during the early stage of alloxan-induced diabetes. Biochem Biophys Acta 165: 380-392
35. Hanson TL, Nordlie RC (1970) Liver microsomal inorganic pyrophosphate-glucose phosphotransferase and glucose-6-phosphatase. Effects of diabetes and insulin administration in kinetic parameters. Biochem Biophys Acta 198: 66-75

36. Newgard CB, Foster DW, McGarry JD (1984) Evidence for suppression of hepatic glucose-6-phosphatase with carbohydrate feeding. Diabetes 33: 192-195

37. Burns TW, Langley $P$ (1958) Observations on lipolysis with isolated adipose tissue cells. J Lab Clin Med 72: 813-823

38. Koranyi L (1983) Lipolytic effect of glucagon on perifused isolated human fat cells. Diabetologia 25: 172 (Abstract)

39. Cherrington AD, Vranic M (1974) Effect of interaction between insulin and glucagon on glucose turnover and FFA concentration in normal and depancreatized dogs. Metabolism 23:729-744

40. Corry DL (1970) Glucagon potentiation of insulin secretion by the perfused rat pancreas. Diabetes 19: $420-428$

41. LeFebvre PJ (1983) Glucagon and adipose tissue lipolysis. In: LeFebvre P (ed) Handbook of Experimental Pharmacology, Vol66, I. Springer, Berlin Heidelberg New York Tokyo, pp 419-440

42. Foster DW, McGarry JD (1982) The regulation of ketogenesis. In: Metabolic acidosis. Pitman, London (Ciba Foundation Symposium 87) pp 120-131

Received: 26 August 1986

and in revised form: 3 February 1987

Dr. H. L.A. Lickley

c/o Department of Physiology

Room 3358, Medical Sciences Building

King's College Circle

University of Toronto

Toronto, Ontario

Canada M5S 1A8 